\title{
IDENTIFIKASI TELUR NEMATODA PADA FESES TERNAK BABI DI DESA KALASEY SATU KECAMATAN MANDOLANG KABUPATEN MINAHASA PROVINSI SULAWESI UTARA
}

\author{
Albert J. Podung*, Jantje Ferdinand Paath, Juliance H. W. Ponto \\ Fakultas Peternakan Univesitas Sam Ratulangi, Manado 95115
}

\begin{abstract}
ABSTRAK
Penelitian ini bertujuan mengetahui dan mengidentifikasi parasit cacing nematoda melalui pemeriksaan telur cacing pada feses ternak babi. Jumlah telur cacing mengindikasikan tingkat serangan parasit. Oleh karena itu, penelitian ini menggunakan sampel kotoran (feses) babi yang dikoleksi dari ternak babi di Desa Kalasey Satu, Kecamatan Mandolang Kabupaten Minahasa. Sampel akan diuji dengan menggunakan metode apung untuk melihat telur-telur cacing. Identifikasi telur cacing dilakukan di Laboratorium Fakultas Peternakan UNSRAT dan dianalisis secara deskriptif serta jumlah telur cacing dihitung untuk melihat tingkat serangannya pada ternak babi. Hasil penelitian ini mendapati, bahwa dari 23 ekor babi yang diambil sampel fesesnya ditemukan 8 sampel feses yang teridentifikasi terinfeksi cacing Ascaris sp. dan 1 di antaranya terinfestasi Oesophagustomum sp. Tiga sampel feses dari babi berumur 3 bulan terinfeksi Ascaris sp dan Oesophagustomum sp. ( 2 sampel mengandung Ascaris sp dan 1 sampel mengandung Oesophagustomum sp.); 5 sampel feses babi induk mengandung telur cacing Ascaris sp. Kesimpulan penelitian ini, bahwa ternak babi yang berada di area peternakan Desa Kalasey Satu, telah terinfestasi cacing Ascaris sp. dan Oesophagustomum sp. dengan prevalensi masing-masing sebesar 30,4\% dan 4,3\%. Kondisi peternakan, pola pemberian pakan dan lingkungan sekitar kendang
\end{abstract}

\footnotetext{
*Korespondensi(corresponding Author)

Email: albertjootjep@unsrat.ac.id
}

sangat mendukung pertumbuhan dan perkembangbiakan induk semang antara bagi endoparasit (cacing)

Kata Kunci: Telur, nematode, feses, babi

\begin{abstract}
IDENTIFICATIOS

OF

NEMATODE EGGS IN PIG'S FAECES

IN KALASEY SATU MANDOLANG, DISTRICT OF MINAHASA OF SULAWESI UTARA PROVINCE. This study aims to determine and identify parasitic nematode worms through examination of worm eggs in pig feces. The number of worm eggs indicates the level of parasitic attack. Therefore, this study uses samples of pig manure collected from pigs in the Kalasey Satu Village, Mandolang District, Minahasa Regency. Samples will be tested using the floating method to see worm eggs. Worm egg identification was carried out in the laboratory of the Faculty of Animal Husbandry UNSRAT and analyzed descriptively and the number of worm eggs was calculated to see the level of attack on pigs. The results of this study found that from 23 pigs that had taken their faecal samples, 8 faecal samples were identified as being infected with Ascaris sp. and 1 of them was infested with Oesophagustomum sp. Three faecal samples from 3 month old pigs infected by Ascaris sp 2 samples containing Ascaris sp. and 1 sample containing Oesophagustomum sp.); 5 fecal samples of sows containing Ascaris sp. The conclusion of this study, that pigs that are in the area of Kalasey Satu Village have been infected by
\end{abstract}


Ascaris sp. and Oesophagustomum sp. with a preavalence of $30,4 \%$ and $4,3 \%$. Livestock conditions, feeding patterns and the environment around the cage are verry supportive of the growth and propagation of the intermediate host of endoparasites.

Keywords: Egg, nematode, feces, pig

\section{PENDAHULUAN}

Keunggulan pemeliharaan ternak babi yaitu produktivitas dan efisiensi pakan yang cukup tinggi. Selain itu, ternak babi memiliki litter size yang tinggi, di mana anak babi yang dilahirkan berkisar 6 sampai 12 ekor dalam 1 kali kelahiran dan induk babi betina dapat melahirkan sebanyak 2 kali per-tahunnya, siklus reproduksi yang relative pendek, tingkat pertumbuhan yang cepat dan efisien dalam penggunaan ransum dan dapat memanfaatkan sisa makanan yang tidak digunakan manusia (Supriadi et al., 2014). Adapun kelemahannya yaitu ternak babi sangat rentan terhadap serangan penyakit (Guna et al., 2014).

Sebagian besar pola pemeliharaan ternak babi di Minahasa dan wilayah lain Sulawessi Utara masih dilakukan secara tradisional. Pola pemeliharaan sederhana tanpa memperhatika manajemen kesehatan ternaknya dan pola pemberian pakan tanpa memperhatikan keseimbangan pakan, dapat menyebabkan penurunan produktivitas ternak. Sanitasi kandang dan lokasi kandang yang berdekatan dengan pemukiman berpotensi penyebaran agen- agen penyakit yang bersifat infeksius, diantaranya penyakit parasite cacing.

Jenis cacing nematode sering menginfeksi ternak babi. Cacing nematode bersifat parasiter yang dapat menginfeksi hewan dan manusia. Beberapa cacing nematode yang sering menginfeksi usus halus babi, antara lain: Trichinella spiralis, Ascaris suum, Trychostrongyloides axei, Strongyloides ransomi, Globocepalus sp., dan Macracathorhyncus hirudinaceus. Infeksi cacing nematode pada ternak dapat menyebabkan enteritis, diare, hilang nafsu makan, lemah, turunnya pertumbuhan dan kematian (Myer and Brendemuhl, 2003). Menurut Marcos et al. (2011), kelompok endoparasit nematode dapat mengakibatkan penurunan hingga 5\% asupan pakan harian pada ternak yang terinfeksi dan menyebabkan penurunan berat badan rata-rata hingga $31 \%$ dan meningkatkan rasio konversi pakan ratarata hingga $17 \%$. Lokasi kandang yang berdekatan dengan pemukiman, pemberian pakan yang tidak teratur dan sanitasi kadang dan lingkungan yang buruk yang menunjang. perkembangbiakan induk semang antara, dapat menjadi potensi terserangnya agen penyakit pada ternak, contohnya parasite cacing (Marcos et el., 2011). Kondisi tersebut dapat ditemukan pada peternakan babi rakyat yang ada di wilayah Desa Kalasey Satu Kecamatan Mandolang Kabupaten Minahasa. Hal ini 
menjadi perlu untuk dilakukan penelitian tentang infeksi parasite nematode di peternakan wilayah tersebut. Penelitian ini bertujuan mengidentifikasi jenis parasite nematode pada ternak babi dan tingkat serangannya.

Penelitian ini bertujuan mengetahui dan mengidentifikasi parasit cacing nematoda melalui pemeriksaan telur cacing pada feses ternak babi. Jumlah telur cacing mengindikasikan tingkat serangan parasit. Oleh karena itu, penelitian ini menggunakan sampel kotoran (feses) babi yang dikoleksi dari ternak babi di Desa Kalasey Satu, Kecamatan Mandolang Kabupaten Minahasa.

\section{MATERI DAN METODE PENELITIAN}

\section{Waktu dan Materi Penelitian}

Panelitian ini dilakukan pada
peternakan babi yang berada di Desa
Kalasey Satu Kecamatan Mandolang Kabupaten Minahasa. Penelitian dilaksanakan dalam waktu 3 bulan, diawali survey lokasi kandang ternak babi yang memiliki 3 kelompok umur yaitu umur 1 bulan, umur 3 bulan dan kelompok ternak induk. Sampel feses diambil dari 23 ekor babi yang terdiri dari: sampel feses 4 ekor berumur 1 bulan, sampel feses 9 ekor babi berumur 3 bulan dan sampel fese dari 10 ekor induk babi.
Alat

Peralatan yang digunakan dalam penelitian ini, yaitu tabung sampel feses, sendok untuk koleksi feses, pipet, tabung, gelas ukur, larutan garam jenuh, alat pengaduk dan mikroskop cahaya.

\section{Metode Penelitian}

Dalam pemilihan sampel ternak babi yang akan diambil fesesnya, dipilih pada kelompok ternak yang tidak diberikan obat cacing. Dengan demikian data yang didapatkan menunjukkan prevalensi cacingan pada ternak dalam satu kawasan ternak babi.

Penelitian ini diawali pada tahap pengambilan sampel ternak babi berdasarkan kelompok umur. Kelompok I, sampel feses yang diambil dari kelompok ternak babi berumur di bawah 3 bulan; kelompok II kelompok babi umur 3-6 bulan dan kelompok III, sampel feses yang diambil dari kelompok induk dan pejantan ternak babi. masing-masing sampel feses yang diambing sebanyak 10 gram. Dari sampel feses yang dikoleksi, mendapatkan 23 data dari kelompok ternak babi berumur di bawah 1 bulan 4 ekor, sampel fese dari babi berumur 3 bulan sebanyak 10 ekor dan 9 sampel feses dari ternak induk (berumur lebih dari 1 tahun). Sampel feses yang diambil dari 23 ekor ternak babi tersebut dilakukan uji apung untuk melihat telur 
cacing dengan menggunakan mikroskop cahaya pembesaran kecil ( $10 \mathrm{X} 45)$.

Metode yang digunakan pada penelitian ini yaitu metode deskriptif dengan melihat keberadaan telur cacing dalam sediaan feses ternak babi. Sampel feses dilakukan uji untuk melihat telur cacing nematoda dengan teknik natif dan uji apung (Kartasudjana, 2001).

Metode Natif:

Feses babi sebesar 1 butir beras ditarus di atas objek glass, ditambah satu tetes air kemudian dicampur. Campuran feses dan air ditutup dengan gelas penutup dan diperiksa di bawah mikroskop dengan pembesaran $10 \times 45$.

Metode Apung:

Sekitar 5 gram feses babi ditaruh ke dalam tabung sentrifus, ditambah air sampai $2 / 3$ tabung lalu diaduk. Dibiarkan beberapa menit lalu air dan bahan yang terapung dibuang secara hati-hati. Selanjutnya tabung disentrifus selama 10 menit dengan kecepatan 5000 rpm. Cairan dibuang secara hati-hati, kemudian ke dalam tabung ditambahkan larutan $\mathrm{NaCl}$ jenuh sampai $2 / 3$ tabung. Kemudian diaduk dan disentrifus lagi sekitar 10 menit. Tabung diambil dari mesin sentrifus dan diletakkan berdiri pad arak tabung, kemudian ditambahkan perlahan larutan $\mathrm{NaCl}$ jenuh. Diamkan sekitar 5 menit, cairan yang cembung ditempelkan pada objek glass, kemudian diperiksa di bawah mikroskop.

Telur cacing yang ditemukan diidentifikasi, dan dihitung prevalensi pada kelompok sampel yang diuji, menggunakan rumus ((Zajac and Conboy, 2012):

$\sum$ Sampel mengandung

Prevalensi $=\frac{\text { telur cacing }}{\sum \text { Seluruh sampel }} \times 100 \%$

\section{Variabel}

Penelitian deskriptif dengan melihat keberadaan telur nematode dalam feses pada 3 kelompok ternak, yaitu: kelompok anak babi berumur $<1$ bulan; kelompok anak babi berumur $1-3$ bulan dan kelompok induk babi.

\section{Analisis Data}

Data telur yang diperoleh dianalisi secara deskriptif dengan menghitung prevalensi menggunakan rumus prevalensi (Zajac and Conboy, 2012).

\section{HASIL DAN PEMBAHASAN}

Hasil pengamatan selama penelitian didapati infestasi cacing pada ternak di lokasi kandang Desa Kalasey Satu Kabupaten Minahasa, yaitu: telur cacing Ascaris sp. dan Oesophagustomum sp. Penelitian ini mendapatkan hasil dari 23 sampel feses yang diamati, ditemukan 8 
sampel feses yang mengandung telur cacing Ascaris sp. dan Oesophagustomum sp (Grafik Infestasi Telur Cacing). Pada kelompok ternak berumur 1 bulan, dari 4 sampel feses yang diamati, tidak ditemukan telur cacing. Sampel feses dari 10 ekor babi berumur 3 bulan ditemukan telur cacing Ascaris sp. dan Oesophagustoumum sp (2 sampel mengandung Ascaris sp dan 1 di antaranya mengandung telur cacing Ascaris dan Oesophagustomum sp.). Pada kelompok induk, dari 9 sampel feses yang diamati, 5 sampel diantaranya mengandung telur cacing Ascaris sp. Prevalensi cacingan pada kelompok ternak di Desa Kalasey Satu Kecamatan Mandolang Kabupaten Minahasa yang dihitung menurut rumus prevalensi, yaitu 34,8\% atau 35\% (Prevalensi Ascaris sp. 34,8\% dan Prevalensi Oesophagustomum sp. 3,4\%). Kriteria prevalensi yang didapatkan dari penelitian ini yaitu pada tingkat serangan yang sedang (Prevalensi Ascaris sp. Kategori sedang, sedangkan prevalensi Oesophagustomum sp. Kategori ringan). Berdasarkan hasil penelitian (Tabel 1.), prevalensi endoparasit Ascaris sp. dan Oesophagustomum sp. pada kelompok ternak babi di Desa Kalasey Satu sebesar $34,7 \%$. Didapatkan prevalensi cacing Ascaris sp tertinggi, yaitu 30,4\%, dengan kelompok ternak induk terinfeksi dengan tingkat prevalensi $21,7 \%$ dan ternak babi berumur > 3 bulan dengan tingkat prevalensi $8,7 \%$. Hal ini berbeda dengan penelitian Guna et al. (2014) yang mendapatkan bahwa tingkat prevalensi cacing Ascaris suum lebih banyak pada kelompok ternak babi penggemukan, yaitu sebesar $20 \%$ dan diantaranta sebesar $15 \%$ ditemukan di dalam saluran pencernaan babi. Penelitian Agnes et al. (2017) mendapatkan tingkat prevalensi cacing Ascaris suum sebesar $15 \%$ pada kelompok ternak siap potong di Rumah Potong Hewan. Tingkat infestasi cacing Ascaris suum yang tinggi didapatkan pada penelitian Erna dan Nova (2019). Penelitian yang dilakukan berdasarkan perbedaan antara kelompok ternak babi jantan dan betina ini, mendapatkan hasil tingkat infestasi cacing Ascaris suum yang tinggi, yaitu pada kelompok ternak jantan sebesar $79,17 \%$ sedangkan pada ternak betina sebear $66,7 \%$. Sedangkan penelitian yang dilakukan oleh Intan et al. (2016), didapati tingkat prevalensi cacing Ascaris sp yang rendah yaitu 9\%. Tingkat prevalensi cacing Oesophagustomum sp. pada penelitian ini didapatkan hasil yaitu 4,3\%. Hasil ini dapat dikatakan bahwa tingkat infestasi cacing Oesophagustomum sp. pada ternak babi yang berada di Desa Kalasey Satu adalah rendah. Telur cacing Oesophagustomum sp. hanya ditemukan pada ternak masa penggemukan (> 3 bulan). Hasil ini, didukung oleh penelitian yang dilakukan oleh Novelin (2015) yang 
Tabel 1.Prevalensi infeksi telur cacing Nematoda pada feses 3 kelompok ternak babi di desa Kalasey Satu Kecamatan Mandolang Kabupaten Minahasa

\begin{tabular}{lcccc}
\hline \multirow{2}{*}{ Jenis Cacing } & \multicolumn{3}{c}{ Prevalensi (\%) } & \multirow{2}{*}{ Total } \\
\cline { 2 - 4 } & $<1$ bulan & $>3$ bulan & Induk & \\
\hline Ascaris sp. & 0 & 8,7 & 21,7 & 30,4 \\
Oesophagustomum sp. & 0 & 4,3 & 0 & 4,3 \\
Total & 0 & 13 & 21,7 & 34,7 \\
\hline
\end{tabular}

yang mendapati tingkat prevalensi yang ringan yaitu $2 \%$. Pelitian yang mendukung juga dilakukan oleh Laszlo (2018), bahwa infestasi cacing Oesophagustomum sp. sering ditemukan pada kelompok ternak babi penggemukan. Sedangkan infestasi cacing Oesophagustomum sp. yang sangat tinggi, yaitu $84,5 \%$ didapati pada sampel babi di pegunungan Polandia (Marcin et al., 2010).

Kondisi peternakan babi yang terdapat di Desa Kalasey Satu, pada umumnya dilakukan dengan pola pemeliharaan secara tradisional. Dalam satu kawasan peternakan yang terdiri dari beberapa pemilik ternak dengan pola pemberian pakan yang berbeda. Beberapa peternak memberi pakan campuran konsentrat dengan jagung dan dedak dengan komposisi yang tidak berimbang, tergantung pada harga masing-masing pakan. Sebagian peternak masih memberi pakan dari makanan sisa rumah makan.
Selain itu, manajemen kesehatan ternak tidak menjadi perhatian dalam pemeliharaan ternak. Sanitasi kadang yang kurang diperhatikan, pemberian obat cacing yang sering tidak dilakukan. Kondisi demikian dapat bagi menjadi potensi terhadap penularan agen penyakit seperti endoparasit (cacing) di antara ternak satu dengan ternak lainnya. Lingkungan yang mendukung kelangsungan induk semang antara bagi cacing juga dapat ditemukan di sekitar kadang, seperti kolam dan rerumputan.

\section{KESIMPULAN}

Ternak babi yang berada di area peternakan Desa Kalasey Satu, telah terinfestasi cacing Ascaris sp. dan Oesophagustomum sp. dengan prevalensi masing-masing sebesar $30,4 \%$ dan $4,3 \%$. Kondisi peternakan, pola pemberian pakan dan lingkungan sekitar kandang ternak babi 
di Desa Kalasey Satu sangat mendukung pertumbuhan dan perkembangbiakan induk semang antara bagi endoparasit (cacing).

\section{SARAN}

Perlu dilakukan penelitian lanjutan dengan menggunakan metode lainnya, seperti dengan menggunakan metode kombinasi antara metode apung dan metode sedimen atau dengan parameter pengamatan infestasi cacing pada kelompok ternak jantan dan betina. Metode perhitungan jumlah telur cacing pada sampel feses juga dapat menjadi bahan untuk diteliti.

\section{UCAPAN TERIMAKASIH}

Ucapan terimakasih kepada Lembaga Penelitian dan Pengabdian Kepada Masyarakat Universitas Sam Ratulangi yang mebantu pembiayaan penelitian ini melalui DIPA UNSRAT Tahun 2019.

\section{DAFTAR PUSTAKA}

Agnes, Y., Muthaqien dan M. Hanafiah. 2017. Identifikasi parasit Nematoda pada usus halus babi (Sus scrofa domesticus) di Rumah Potong Hewan Medan Sumatera Utara. JIMVET 01(3): 473-476

Erna, P. dan H. Nova. 2019. Prevalensi dan intensitas telur cacing parasit gastrointestinal pada ternak babi (Sus scrofa domesticus L.). Jurnal Bioterdidik 4: 69-80.

Guna, I.N., N.A. Suratman, dan I. M. Pariyasa. 2014. Infeksi cacing Nematoda pada usus halus babi di Lembah Balien dan Pegunungan Arfak Papua. Buletin Veteriner Udayana 6(2): 129-134.

Intan, T., W. Junus, T.L. Leonardo, dan I. Rina. 2016. Parasit gastrointestinal pada hewan ternak di tempat pemotongan hewan Kabupaten Sigi, Sulawesi Tengah. BALABA 12(2): 71-78.

Kartasudjana R. 2001. Tehnik Kesehatan Ternak. Modul Program Keahlian Budidaya Ternak, Departemen Pendidikan Nasional. Proyek Pengembangan Sistem dan Standard Pengelolaan SMK. Direktorat Pendidikan Menengah Kejuruan Jakarta.

Laszlo, O. 2018. Production impact of parasitisme and coccidiosis in swine, Review Article. Journal of Diary, Veterinary and Animal Research 7(5): 217-222.

Marcin, P., T.D. Knech, J. Szczesna and C.R. Agneszka. 2010. Helminth of the wild boar (Sus scrofa L.) in natural and breeding conditions. Bull. Vet. Inst. Pulawy 54: 161-166.

Marcos, K., I. Andretta, S. Monteiro, P.A. Lovatto, and C.R. Lehnen. 2011. Meta-analysis of the effects of endoparasite on pig performance. Veterinary Parasitology 181:316-320.

Myer, R.O. and J.H. Brendemuhl. 2003. Controlling Internal Parasites in Swine. AS50. The Animal Science Departement's series, UF/ Extension. 
Novelin, I. 2015. Identifikasi Cacing Nematoda pada Saluran Pencernaan Babi di Makassar. Skripsi. Program Studi Kedokteran Hewan Fakultas Kedokteran, Universitas Hasanuddin, Makassar.

Supriadi, A. Muslihin dan B. Roesmanto. 2014. Pre-Eliminasi Parasit gastrointestinal pada babi dari Desa Suranadi Kecamatan Lombok Barat. Media Bina Ilmiah 8(5): 64-68.

Zajac, A.M. dan G.A. Conboy. 2012. Veterinary Clinical Parasitologists. Wiley-Blackwell, A John Wiley \& sons,Inc. Publication. 